\title{
Detection of anti-pertussis toxin lgG in oral fluids for use in diagnosis and surveillance of Bordetella pertussis infection in children and young adults
}

\author{
David J. Litt, ${ }^{1}$ Dhanraj Samuel, ${ }^{2}$ John Duncan, ${ }^{1}$ Anthony Harnden, ${ }^{3}$ \\ Robert C. George ${ }^{1}$ and Timothy G. Harrison ${ }^{1}$ \\ ${ }^{1,2}$ Respiratory and Systemic Infection Laboratory ${ }^{1}$ and Virus Reference Department ${ }^{2}$, Centre for \\ Infections, Health Protection Agency, 61 Colindale Avenue, London NW9 5EQ, UK \\ ${ }^{3}$ Department of Primary Healthcare, University of Oxford, Old Road Campus, Headington, \\ Oxford OX3 7LF, UK
}

Correspondence

David J. Litt

david.litt@hpa.org.uk

Received 26 January 2006

Accepted 7 June 2006

\section{INTRODUCTION}

The bacterium Bordetella pertussis causes potentially lifethreatening whooping cough in humans. Childhood immunization with whole-cell or acellular vaccines, however, has dramatically reduced the incidence of severe disease and it is generally only seen in unvaccinated infants (Cherry, 1996; Heininger, 2001). Nevertheless, it has become increasingly recognized that vaccine-derived immunity wanes over 5-10 years and that $B$. pertussis also causes a prolonged cough with milder symptoms in previously vaccinated older children and adults (Cherry, 1999; von König et al., 2002). Indeed, siblings and parents with coughing symptoms are an important source of infection for unvaccinated babies (Orenstein, 1999; Crowcroft et al., 2003). Diagnosis of infection in this older population is important for

Abbreviations: GACELISA, IgG antibody-capture ELISA; HPA, UK Health Protection Agency; HRP, horseradish peroxidase; NPA, nasopharyngeal aspirate; PPV, positive predictive value; PT, pertussis toxin; TMB, 3,3',5,5'-tetramethylbenzidine. surveillance purposes, and may help prevent transmission to unvaccinated babies, with their attendant high morbidity and mortality.

Elevated serum IgG titres against pertussis toxin (PT) are widely accepted as a reliable marker of recent or persisting infection (Hallander, 1999; Yih et al., 2000; de Melker et al., 2000; Giammanco et al., 2003). In the UK, the Health Protection Agency (HPA) Centre for Infections employs an indirect ELISA for diagnostic and surveillance purposes in which a serum anti-PT IgG titre of $\geqslant 100 \mathrm{eU} \mathrm{ml}^{-1}$ is consistent with recent or current ( $\geqslant 2$ weeks) infection (Giammanco et al., 2003). A recent study using this serum ELISA estimated the prevalence of $B$. pertussis infection amongst children aged 5-16 years with chronic coughs lasting at least 2 weeks as $37 \%$ (Harnden et al., 2006). Other studies in Europe and the USA, using serology in combination with culture and PCR detection, have estimated infection at between 12 and $32 \%$ in coughing subjects (Birkebaek et al., 1999; Cherry, 1999; Gilberg et al., 2002; Miller et al., 2000; Senzilet et al., 2001) and between 
0.3 and $2.8 \%$ in the general population (Miller et al., 2000; Nardone et al., 2004; Strebel et al., 2001).

There is a growing interest in studying anti-PT serum IgG titres for diagnosis and surveillance of pertussis disease, particularly amongst children and adults with prolonged coughing symptoms. However, taking blood can be distressing to patients, especially children. In order to avoid the distress and risks associated with sampling blood, we have devised an IgG antibody-capture ELISA (GACELISA) capable of detecting anti-PT IgG in oral fluid. Oral fluid, collected from the gingival crevice using an absorbent device, contains ratios of specific to total IgG representative of those present in serum (Mortimer \& Parry, 1988; McKie et al., 2002). We present data on the sensitivity and specificity of the oral fluid assay when used as a surrogate for the serum ELISA currently used in our laboratory.

\section{METHODS}

Subjects and samples. One hundred and eighty-seven matched oral fluid and serum samples were taken from 154 children (i.e. 33 children gave two samples at different times) aged 5-16 years when presenting to a general practitioner with a cough of at least 2 weeks' duration (Harnden et al., 2006). These samples were collected, with informed consent, following approval of the Oxfordshire research ethics committee. For comparison, oral fluid samples were taken from 220 control children, also aged 5-16 years, who had been suspected of having measles, mumps or rubella infection, but whose oral fluid scored negative for antibodies to these viruses. These samples were selected to provide an approximate age match to the 187 samples described above, and were collected anonymously from those submitted for measles, mumps or rubella testing to the HPA Enteric, Respiratory and Neurological Virus Laboratory. Serum was not available for the control subjects.

Oral fluid was collected using an Oracol swab (Malvern Medical Developments) and sent to the laboratory by mail. The fluid was eluted from each swab using $1 \mathrm{ml}$ transport medium, as described earlier (Sheppard et al., 2001), and stored at $-20^{\circ} \mathrm{C}$. Blood was collected into Vacutainer tubes (Becton Dickinson) and sent to the laboratory by mail. Serum was extracted by centrifugation and stored at $4{ }^{\circ} \mathrm{C}$.

Indirect ELISA for anti-PT IgG in serum. Serum anti-PT IgG titres were determined using an indirect ELISA, essentially as described previously (Giammanco et al., 2003). Any titres $<4 \mathrm{eU} \mathrm{ml}^{-1}$ were scored as $=4 \mathrm{eU} \mathrm{ml}^{-1}$ for data analysis.

Preparation of reagents for oral fluid ELISA. Rabbit antihuman IgG (Dako Cytomation) was absorbed using an immunosorbent consisting of sheep serum proteins linked to Sepharose $4 \mathrm{~B}$ by standard procedures (Hudson \& Hay, 1980). IgG fraction of sheep anti-PT serum 97/572 (National Institute for Biological Standards and Control) was obtained after anion-exchange chromatography using DEAE-cellulose (Sigma) and conjugated to horseradish peroxidase (HRP), as described by Wilson \& Nakane (1978).

GACELISA for anti-PT IgG in oral fluid. All steps contained $100 \mu \mathrm{l}$ per well unless stated otherwise. Microtitre plate wells (Maxisorp, Nunc) were coated overnight at $4{ }^{\circ} \mathrm{C}$ with absorbed rabbit anti-human IgG (described above) that had been diluted to $2 \mu \mathrm{g} \mathrm{ml}^{-1}$ in $0.05 \mathrm{M}$ carbonate buffer, $\mathrm{pH} 9 \cdot 6$. Wells were washed (four times) with PBST (PBS $+0.05 \%, \mathrm{v} / \mathrm{v}$, Tween 20 ) and incubated with $200 \mu \mathrm{l}$ per well of blocking solution $(5 \%$, w/v, Solupro; Microimmune) at $37^{\circ} \mathrm{C}$ for $2 \mathrm{~h}$.
During the blocking step, oral fluid samples were prepared by mixing them $1: 1$ with serum diluent (PBS containing $1 \%$, w/v, skimmed milk and $0.05 \%, v / v$, Tween 20 ). Reference sera were diluted $1 / 2000$ in serum diluent. The lyophilized human anti-PT serum 89/530 (National Institute for Biological Standards and Control) was hydrated in PBS to one-tenth of the recommended concentration and then diluted 1/80 in serum diluent (resulting in a final total IgG concentration of $5 \mu \mathrm{g} \mathrm{ml}^{-1}$ ). This was defined as producing 1000 arbitrary units $(\mathrm{AU})$ in the ELISA and was diluted serially in a negative serum (also diluted in serum diluent to produce an IgG concentration of $5 \mu \mathrm{g} \mathrm{ml}^{-1}$ ) in order to generate a standard curve on each plate that contained a consistent concentration of total $\operatorname{IgG}$ in every well.

Following the blocking step, wells were washed with PBST and the oral fluid and serum samples incubated in the wells for $2 \mathrm{~h}$ at $37^{\circ} \mathrm{C}$. Wells were washed again and incubated with purified PT (produced by GlaxoSmithKline, available from the National Institute for Biological Standards and Control) at a concentration of $1 \mu \mathrm{g} \mathrm{ml}^{-1}$ in PBS containing $3 \%(\mathrm{w} / \mathrm{v})$ BSA and $0 \cdot 2 \%(\mathrm{v} / \mathrm{v})$ Tween 20 , and incubated for $1 \mathrm{~h}$ at $37^{\circ} \mathrm{C}$. Following another wash step, sheep anti-PT-HRP conjugate antibodies (see above) were diluted in serum diluent and added to the wells for $1 \mathrm{~h}$ at $37^{\circ} \mathrm{C}$. Wells were washed a final time and incubated with 3,3' $5,5^{\prime}$-tetramethylbenzidine (TMB; Microimmune) for $10 \mathrm{~min}$. The reaction was stopped by adding $50 \mu \mathrm{l} 2 \mathrm{M} \mathrm{H}_{2} \mathrm{SO}_{4}$ per well. Absorbance at $620 \mathrm{~nm}$ was subtracted from that at $450 \mathrm{~nm}$ for each well using a Multiskan EX microtitre plate reader and Genesis software (Thermo Labsystems). The titre of PT-specific IgG was calculated (in AU) for each sample by comparison to a four-parameter standard curve fitted to the serially diluted standard serum. Titres $>1000 \mathrm{AU}$ were scored as $=1000 \mathrm{AU}$ for data analysis.

ELISA for quantifying total IgG. All steps contained $100 \mu \mathrm{l}$ per well unless stated otherwise. Maxisorp microtitre plate wells (Nunc) were coated overnight at $4{ }^{\circ} \mathrm{C}$ with rabbit anti-human IgG (DAKO Cytomation) at $2 \mu \mathrm{g} \mathrm{ml}^{-1}$ in carbonate buffer, $\mathrm{pH} 9 \cdot 6$. Wells were washed (four times) with PBST and then incubated with $200 \mu \mathrm{l}$ per well of blocking solution (described above) at $37^{\circ} \mathrm{C}$ for $2 \mathrm{~h}$. During the blocking step, oral fluid or serum samples were diluted to a range of dilutions in serum diluent (described above). A human serum protein calibrator (DAKO Cytomation) was serially diluted in serum diluent to give total IgG concentrations between 800 and $0.78 \mathrm{ng} \mathrm{ml}^{-1}$ in order to generate a standard curve for each plate. Following the blocking step, wells were washed with PBST and the oral fluid and serum samples incubated in the wells for $1 \mathrm{~h}$ at $37^{\circ} \mathrm{C}$. Wells were washed again and an HRP-conjugated rabbit anti-human IgG antibody (Sigma), diluted in PBS containing 3\% (w/v) BSA, $0.05 \%(\mathrm{v} / \mathrm{v})$ Tween 20 and $0.05 \%$ Bronidox-L, was incubated in the wells for $1 \mathrm{~h}$ at $37^{\circ} \mathrm{C}$. Wells were washed a final time and incubated with TMB for 5 min. The reaction was stopped by adding $50 \mu \mathrm{l} 2 \mathrm{M} \mathrm{H}_{2} \mathrm{SO}_{4}$ per well. Absorbance at $620 \mathrm{~nm}$ was subtracted from that at $450 \mathrm{~nm}$ for each well using a Multiskan EX microtitre plate reader and Genesis software. The concentration of IgG in each sample was calculated by comparison to a four-parameter standard curve fitted to the serially diluted standard.

\section{RESULTS AND DISCUSSION}

\section{Correlation between serum and oral fluid anti-PT IgG titres}

The concentration of total IgG in oral fluids collected with an Oracol swab from the 187 children (aged 5-16 years) with prolonged coughs ( $\geqslant 2$ weeks) used in this study varied between 0.33 and $23 \cdot 1 \mu \mathrm{g} \mathrm{ml}^{-1}$ (median $2 \cdot 5 \mu \mathrm{g} \mathrm{ml}^{-1}$ ). A GACELISA was used to analyse oral fluid IgG, since this 
format accommodates samples containing varied concentrations of antibody, on the condition that all samples contain sufficient antibody to saturate the capture antibody layer. Preliminary experiments showed that the anti-IgG capture antibody layer was saturated by IgG concentrations in oral fluid above $\sim 0.75 \mu \mathrm{g} \mathrm{ml}^{-1}$ (results not shown). GACELISA has previously proven useful in the surveillance of other infections, such as measles, mumps and rubella (Perry et al., 1993), and is less prone to non-specific interactions than indirect ELISA (D. J. Litt and others, unpublished results). In this particular assay, a capture antibody is used to immobilize IgG from the oral fluid, after which soluble PT is added, which binds to any specific antibody present. Finally, a PT-specific HRP conjugate is added to quantify the amount of immobilized PT.

The anti-PT IgG titres generated by oral fluids from the 187 children with prolonged coughs correlated well with their matched sera (Fig. 1). A line of best fit (based on a power relationship between the variables) generated the correlation coefficient $R^{2}=0 \cdot 75$, and suggested that a subject with a serum titre of $100 \mathrm{eU} \mathrm{ml}^{-1}$ (i.e. seropositive) would possess an oral fluid titre of $67 \mathrm{AU}$.

\section{Sensitivity and specificity of the oral fluid GACELISA in children with prolonged coughs}

The ability of the oral fluid GACELISA to act as a surrogate for the serum ELISA was tested using matched sera and oral fluids from the same 187 children with prolonged coughs. Of these, 69 were seropositive (serum anti-PT titre $\geqslant 100 \mathrm{eU} \mathrm{ml}^{-1}$ ).

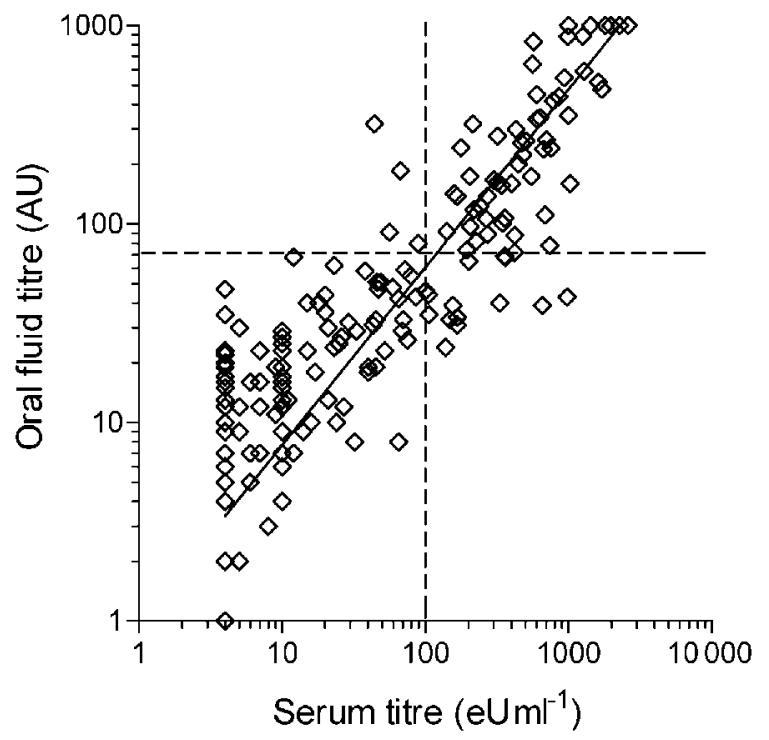

Fig. 1. Comparison of anti-PT IgG titres generated by matched serum and oral fluid samples from 187 children with prolonged coughs. A line of best fit (power relationship) and the serum and oral fluid titre values of $100 \mathrm{eU} \mathrm{ml}^{-1}$ and $70 \mathrm{AU}$, respectively, are highlighted.
The oral fluid anti-PT titres showed some overlap between the seropositive and seronegative groups of coughing children (Fig. 2). Using a cutoff of $70 \mathrm{AU}$, the oral fluid GACELISA showed an overall concordance of 169/187 $(90 \cdot 4 \%)$ with the serum ELISA. This comprised a sensitivity of 55/69 [79.7\%; $95 \%$ confidence interval (CI) 68.3-88.4] and a specificity of $114 / 118(96 \cdot 6 \% ; 95 \%$ CI $91 \cdot 5-99 \cdot 1)$ (Table 1).

The 14 false-negative results and four false-positive results generated by the oral fluid assay in this study did not appear to be associated with patients' ages, the time between disease onset and sampling, or the total concentration of IgG in the oral fluid samples (Table 2). Other studies have reported that samples with low IgG concentrations can generate falsenegative results in GACELISAs (Nigatu et al., 1999), and this cannot be ruled out as the explanation for some of the false negatives seen in this study. Although the IgG capture antibody layer in the assay is saturated when oral fluids contain more than $\sim 0.75 \mu \mathrm{g}$ total $\mathrm{IgG} \mathrm{ml}^{-1}$, we did observe that samples containing $<3 \mu \mathrm{g}$ total IgG ml${ }^{-1}$ may produce suboptimal absorbance values in the assay (results not shown). Nevertheless, other factors are clearly involved in the generation of discordant results, in particular the two strong false-positive oral fluid titres observed in this group. We hypothesize that these oral fluids contained

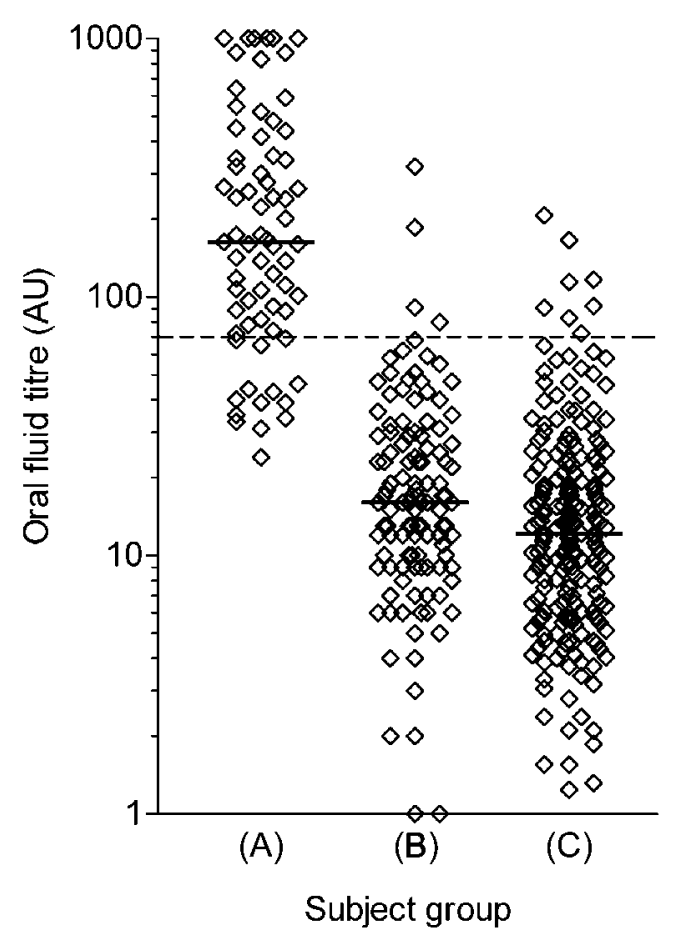

Fig. 2. Anti-PT $\lg G$ titres in $(A)$ oral fluids from 69 seropositive $\left(\geqslant 100 \mathrm{eU} \mathrm{ml}^{-1}\right.$ ) children with prolonged coughs, (B) 118 seronegative children with prolonged coughs, and (C) 220 agematched controls. The median of each population is shown with a horizontal bar. The oral fluid titre value of $70 \mathrm{AU}$ is highlighted with a dashed line. 
Table 1. Sensitivity, specificity and PPV of different cutoff values in the oral fluid anti-PT GACELISA when distinguishing between 69 seropositive $\left(\geqslant 100 \mathrm{eU} \mathrm{ml}^{-1}\right)$ and 118 seronegative children with prolonged coughs

Disease prevalence values of 12,32 and $37 \%$ are representative of those reported in previous studies.

\begin{tabular}{|c|c|c|c|c|c|}
\hline \multirow{2}{*}{$\begin{array}{l}\text { Cutoff value } \\
\text { (AU) }\end{array}$} & \multirow{2}{*}{$\begin{array}{c}\text { Sensitivity } \\
(\%)\end{array}$} & \multirow{2}{*}{$\begin{array}{c}\text { Specificity } \\
(\%)\end{array}$} & \multicolumn{3}{|c|}{ PPV } \\
\hline & & & $12 \%$ prevalence & $32 \%$ prevalence & $37 \%$ prevalence \\
\hline 10 & $100 \cdot 0$ & $25 \cdot 4$ & $15 \cdot 5$ & $38 \cdot 7$ & $44 \cdot 1$ \\
\hline 20 & $100 \cdot 0$ & $61 \cdot 9$ & $26 \cdot 3$ & $55 \cdot 2$ & $60 \cdot 6$ \\
\hline 30 & $98 \cdot 6$ & $50 \cdot 8$ & $21 \cdot 5$ & $48 \cdot 5$ & $54 \cdot 1$ \\
\hline 40 & $89 \cdot 9$ & $83 \cdot 1$ & $42 \cdot 0$ & $71 \cdot 4$ & $75 \cdot 7$ \\
\hline 50 & $84 \cdot 1$ & $90 \cdot 7$ & $55 \cdot 1$ & $80 \cdot 9$ & $84 \cdot 1$ \\
\hline 60 & $84 \cdot 1$ & $94 \cdot 9$ & $69 \cdot 3$ & $88 \cdot 6$ & $90 \cdot 7$ \\
\hline 70 & $79 \cdot 7$ & $96 \cdot 6$ & $76 \cdot 2$ & $91 \cdot 7$ & $93 \cdot 2$ \\
\hline 80 & $75 \cdot 4$ & $96 \cdot 6$ & $75 \cdot 2$ & $91 \cdot 3$ & $92 \cdot 9$ \\
\hline 90 & $71 \cdot 0$ & $97 \cdot 5$ & $79 \cdot 2$ & $92 \cdot 9$ & $94 \cdot 3$ \\
\hline 100 & $68 \cdot 1$ & $98 \cdot 3$ & $84 \cdot 6$ & $95 \cdot 0$ & $95 \cdot 9$ \\
\hline 150 & $55 \cdot 1$ & $98 \cdot 3$ & $81 \cdot 6$ & $93 \cdot 9$ & $95 \cdot 0$ \\
\hline 200 & $44 \cdot 9$ & $99 \cdot 2$ & $87 \cdot 8$ & $96 \cdot 1$ & $96 \cdot 9$ \\
\hline 300 & $31 \cdot 9$ & $99 \cdot 2$ & $83 \cdot 7$ & $94 \cdot 7$ & $95 \cdot 7$ \\
\hline 400 & $24 \cdot 6$ & $100 \cdot 0$ & $100 \cdot 0$ & $100 \cdot 0$ & $100 \cdot 0$ \\
\hline
\end{tabular}

Table 2. Subjects amongst 187 children with prolonged coughs whose matched sera and oral fluids produced discordant anti-PT $\mathrm{lgG}$ titres (seropositive $\geqslant 100 \mathrm{eU} \mathrm{ml}^{-1}$; oral fluid positive $\geqslant 70 \mathrm{AU}$ )

'Onset' refers to the onset of coughing symptoms (y, years; m, months).

\begin{tabular}{|c|c|c|c|c|c|}
\hline Subject & $\begin{array}{l}\text { Serum titre } \\
\left(\mathrm{eU} \mathrm{ml} \mathrm{ml}^{-1}\right)\end{array}$ & $\begin{array}{l}\text { Oral fluid titre } \\
\text { (AU) }\end{array}$ & $\begin{array}{l}\text { Oral fluid IgG } \\
\text { concn }\left(\mu \mathrm{g} \mathrm{ml}^{-1}\right)\end{array}$ & $\begin{array}{l}\text { Time from onset } \\
\text { to sampling (days) }\end{array}$ & Age at onset \\
\hline \multicolumn{6}{|c|}{ False-negative oral fluid result: } \\
\hline A10 & 149 & 33 & $8 \cdot 1$ & 99 & 6 y $9 \mathrm{~m}$ \\
\hline A14 & 168 & 34 & $2 \cdot 7$ & 32 & 11 y $2 \mathrm{~m}$ \\
\hline A27 & 357 & 69 & $1 \cdot 0$ & 46 & 13 y $6 \mathrm{~m}$ \\
\hline A29 & 105 & 44 & $2 \cdot 5$ & 96 & 7 y $11 \mathrm{~m}$ \\
\hline B16 & 138 & 24 & $6 \cdot 4$ & 33 & 6 y 7 m \\
\hline B37 & 201 & 65 & $9 \cdot 4$ & 58 & 5 y $11 \mathrm{~m}$ \\
\hline B48 & 978 & 43 & $2 \cdot 7$ & 64 & 6 y $10 \mathrm{~m}$ \\
\hline C44 & 100 & 46 & $5 \cdot 1$ & 33 & 7 y $10 \mathrm{~m}$ \\
\hline D2 & 656 & 39 & $0 \cdot 8$ & 44 & 6 y $4 \mathrm{~m}$ \\
\hline E16 & 363 & 68 & $2 \cdot 0$ & $45 / 50^{*}$ & 8 y $5 \mathrm{~m}$ \\
\hline E27 & 156 & 39 & $4 \cdot 5$ & 30 & 8 y $9 \mathrm{~m}$ \\
\hline E34 & 106 & 35 & $1 \cdot 1$ & 120 & 12 y $6 \mathrm{~m}$ \\
\hline E36 & 330 & 40 & $6 \cdot 6$ & 29 & 8 y $7 \mathrm{~m}$ \\
\hline $\mathrm{E} 39 / 2$ & 167 & 31 & $1 \cdot 1$ & 21 & 8 y $2 \mathrm{~m}$ \\
\hline \multicolumn{6}{|c|}{ False-positive oral fluid result: } \\
\hline E6 & 56 & 91 & $1 \cdot 1$ & 43 & 12 y $4 \mathrm{~m}$ \\
\hline E7 & 89 & 80 & $1 \cdot 8$ & 28 & 6 y $6 \mathrm{~m}$ \\
\hline B29 & 44 & 320 & $0 \cdot 9$ & 38 & 16 y $6 \mathrm{~m}$ \\
\hline E38 & 43 & 186 & $2 \cdot 0$ & 35 & 5 y $2 \mathrm{~m}$ \\
\hline
\end{tabular}

${ }^{\star} 45$ days for serum, 50 days for oral fluid. 
uncharacterized substances from their subjects' mouths that interfered with the assay.

\section{Positive predictive value of the oral fluid GACELISA in children with prolonged coughs}

It has recently been shown that $37 \%$ of children aged 5-16 in the UK with prolonged coughing symptoms are seropositive for $B$. pertussis infection (Harnden et al., 2006). Using $\geqslant 70 \mathrm{AU}$ as the definition of positivity, the oral fluid GACELISA exhibited a positive predictive value (PPV) of $93.2 \%$ in this population when used as a surrogate for the serum ELISA (i.e. assuming a disease prevalence of $37 \%$; Table 1). The corresponding negative predictive value (NPV) was $89 \cdot 3 \%$. By raising the cutoff in the oral fluid GACELISA to $\geqslant 100 \mathrm{AU}$ it would be possible to increase the PPV to $95 \%$ with only a modest reduction in sensitivity (Table 1).

If the upper and lower limits of disease prevalence shown by other studies (not confined to the 5-16 year age group) of 12 and $32 \%$ in subjects with prolonged coughs are assumed, a 70 AU cutoff results in respective PPVs of 76.2 and $91.7 \%$ (Table 1) and NPVs of $97 \cdot 3$ and $91 \cdot 3 \%$ for the oral fluid GACELISA.

\section{Oral fluid anti-PT IgG titres in control children}

Analysis of oral fluids from 220 control children (Fig. 2) revealed that $8 / 220(3.6 \%)$ possessed anti-PT IgG titres $\geqslant 70$ AU. There were no matched sera for these oral fluid samples in order to compare the results using the serum ELISA. However, this is similar to the result of a recent study in the UK, which showed that $2 \cdot 8 \%$ of normal children aged $<15$ years were seropositive for B. pertussis infection (Nardone et al., 2004). It is encouraging that the oral fluid GACELISA detected a similar incidence of infection as the serum ELISA when used in the general population (irrespective of coughing symptoms).

\section{Reproducibility within and between runs}

Five oral fluid samples (with titres between 23 and 213 AU), assayed five times each within the same run, produced coefficients of variation ranging between 1.9 and $8.3 \%$ (median $3.8 \%$ ). Fifteen oral fluid samples (with titres ranging between 41 and $192 \mathrm{AU}$ ), each assayed on eight independent occasions, produced coefficients of variation of between $5 \cdot 4$ and $18 \cdot 6 \%$ (median $9 \cdot 4 \%$ ).

\section{General comments}

Our results demonstrate that the oral fluid anti-PT GACELISA can be used as a surrogate for the serum ELISA, demonstrating high specificity and PPV in subjects with prolonged coughing symptoms. Even though the assay does not appear to be as sensitive as the serum ELISA, it will be a valuable alternative to the serum anti-PT ELISA, especially in epidemiological studies or for diagnosis in young patients reluctant to provide blood samples. Care would need to be taken when using this ELISA as a surrogate for the serum ELISA in the general population, irrespective of coughing symptoms, however, as the much lower incidence of disease of $0 \cdot 3-2 \cdot 8 \%$ in the general population (Miller et al., 2000; Nardone et al., 2004; Strebel et al., 2001) would result in a corresponding PPV of only $6 \cdot 6-40 \cdot 3 \%$.

To our knowledge, this is the first description of an anti-PT IgG antibody capture assay designed for use with oral fluids. Indirect ELISAs have been used to detect PT-specific IgG in saliva and nasopharyngeal aspirates (NPAs), following disease or intranasal vaccination against pertussis, with disappointing results (Granstrom et al., 1988b; Berstad et al., 2000). This is not surprising, since indirect ELISAs are not ideal for use with samples containing the expected low and variable antibody concentrations in oral fluid (Mortimer \& Parry, 1988). These earlier studies appear not to have analysed the concentration of IgG in the samples, nor did they study the correlation between the PT-specific IgG titre in mucosal fluid and that in serum.

Evaluation of PT-specific IgA along with IgG in oral fluids may be a means of increasing the sensitivity of this diagnostic method, since rises in anti-PT IgA titre in saliva and NPAs are easier to detect than those of IgG following disease or intranasal immunization (Zackrisson et al., 1990; Granstrom et al., 1988a; Berstad et al., 2000). IgA also offers the advantage over IgG that its levels do not increase very strongly after primary parenteral vaccination against pertussis (Goodman et al., 1981; Thomas et al., 1989; Cherry, 1999). Hence, IgA titres may be helpful in detecting infections during the months following vaccination, when IgG levels are uninformative.

\section{ACKNOWLEDGEMENTS}

We are indebted to the participating families, general practitioners and research nurses involved in collecting the matched serum and oral fluid samples. We are grateful to Bernard Cohen, Rashpal Hunjan and colleagues for providing oral fluids from control children, and to David Gelb, Kathleen Baster and Nick Andrews for statistical advice.

\section{REFERENCES}

Berstad, A. K. H., Holst, J., Frohølm, L. O., Haugen, I. L., Wedege, E., Oftung, F. \& Haneberg, B. (2000). A nasal whole-cell pertussis vaccine induces specific systemic and cross-reactive mucosal antibody responses in human volunteers. J Med Microbiol 49, 157-163.

Birkebaek, N. H., Kristiansen, M., Seefeldt, T., Degn, J., Moller, A., Heron, I., Andersen, P. L., Møller, J. K. \& Østergard, L. (1999). Bordetella pertussis and chronic cough in adults. Clin Infect Dis 29, 1239-1242.

Cherry, J. D. (1996). Historical review of pertussis and the classical vaccine. J Infect Dis 174 (Suppl. 3), S259-S263.

Cherry, J. D. (1999). Epidemiological, clinical, and laboratory aspects of pertussis in adults. Clin Infect Dis 28 (Suppl. 2), S112-S117.

Crowcroft, N. S., Booy, R., Harrison, T. \& 8 other authors (2003). Severe and unrecognised: pertussis in UK infants. Arch Dis Child 88, 802-806. 
de Melker, H. E., Versteegh, F. G. A., Conyn-Van Spaendonck, M. A. E., Elvers, L. H., Berbers, G. A., van Der Zee, A. \& Schellekens, J. F. P. (2000). Specificity and sensitivity of high levels of immunoglobulin $G$ antibodies against pertussis toxin in a single serum sample for diagnosis of infection with Bordetella pertussis. J Clin Microbiol 38, 800-806.

Giammanco, A., Chiarini, A., Maple, P. A. C. \& 10 other authors (2003). European Sero-Epidemiology Network: standardisation of the assay results for pertussis. Vaccine 22, 112-120.

Gilberg, S., Njamkepo, E., Du Châtalet, I. P., Partouche, H., Gueirard, P., Ghasarossian, C., Schlumberger, M. \& Guiso, N. (2002). Evidence of Bordetella pertussis infection in adults presenting with persistent cough in a French area with very high whole-cell vaccine coverage. $J$ Infect Dis 186, 415-418.

Goodman, Y. E., Wort, A. J. \& Jackson, F. L. (1981). Enzyme-linked immunosorbent assay for detection of pertussis immunoglobulin A in nasopharyngeal secretions as an indicator of recent infection. J Clin Microbiol 13, 286-292.

Granstrøm, G., Askeløf, P. \& Granstrøm, M. (1988a). Specific immunoglobulin A to Bordetella pertussis antigens in mucosal secretion for rapid diagnosis of whooping cough. J Clin Microbiol 26, 869-874.

Granstrøm, G., Wretlind, B., Salenstedt, C. R. \& Granstrøm, M. (1988b). Evaluation of serologic assays for diagnosis of whooping cough. J Clin Microbiol 26, 1818-1823.

Hallander, H. O. (1999). Microbiological and serological diagnosis of pertussis. Clin Infect Dis 28 (Suppl. 2), S99-S106.

Harnden, A., Grant, C., Harrison, T., Perera, R., Brueggemann, A. B., Mayon-White, R. \& Mant, D. (2006). Whooping cough in school age children with persistent cough: a prospective cohort study in primary care. $B M J$ (in press).

Heininger, U. (2001). Pertussis: an old disease that is still with us. Curr Opin Infect Dis 14, 329-335.

Hudson, L. \& Hay, F. (1980). Affinity chromatography. In Practical Immunology, 2nd edn, pp. 203-215. Oxford, UK: Blackwell Scientific Publications.

McKie, A., Vyse, A. \& Maple, C. (2002). Novel methods for the detection of microbial antibodies in oral fluid. Lancet Infect Dis 2, $18-24$.

Miller, E., Fleming, D. M., Ashworth, L. A., Mabbett, D. A., Vurdien, J. E. \& Elliott, T. S. (2000). Serological evidence of pertussis in patients presenting with cough in general practice in Birmingham. Commun Dis Public Health 3, 132-134.

Mortimer, P. P. \& Parry, J. V. (1988). The use of saliva for viral diagnosis and screening. Epidemiol Infect 101, 197-201.
Nardone, A., Pebody, R. G., Maple, P. A. C., Andrews, N., Gay, N. J. \& Miller, E. (2004). Sero-epidemiology of Bordetella pertussis in England and Wales. Vaccine 22, 1314-1319.

Nigatu, W., Nokes, D. J., Enquselassie, F., Brown, D. W., Cohen, B. J., Vyse, A. J. \& Cutts, F. T. (1999). Detection of measles specific IgG in oral fluid using an FITC/anti-FITC IgG capture enzyme linked immunosorbent assay (GACELISA). J Virol Methods 83, 135-144.

Orenstein, W. A. (1999). Pertussis in adults: epidemiology, signs, symptoms, and implications for vaccination. Clin Infect Dis 28 (Suppl. 2), S147-S150.

Perry, K. R., Brown, D. W., Parry, J. V., Panday, S., Pipkin, C. \& Richards, A. (1993). Detection of measles, mumps, and rubella antibodies in saliva using antibody capture radioimmunoassay. J Med Virol 40, 235-240.

Senzilet, L. D., Halperin, S. A., Spika, J. S., Alagaratnam, M., Morris, A., Smith, B. \& the Sentinel Health Unit Surveillance System Pertussis Working Group (2001). Pertussis is a frequent cause of prolonged cough illness in adults and adolescents. Clin Infect Dis 32, 1691-1697.

Sheppard, C., Cohen, B., Andrews, N. \& Surridge, H. (2001). Development and evaluation of an antibody capture ELISA for detection of IgG to Epstein-Barr virus in oral fluid samples. J Virol Methods 93, 157-166.

Strebel, P., Nordin, J., Edwards, K., Hunt, J., Besser, J., Burns, S., Amundson, G., Baughman, A. \& Wattigney, W. (2001). Populationbased incidence of pertussis among adolescents and adults, Minnesota, 1995-1996. J Infect Dis 183, 1353-1359.

Thomas, M. G., Ashworth, L. A., Miller, E. \& Lambert, H. P. (1989). Serum IgG, IgA, and IgM responses to pertussis toxin, filamentous hemagglutinin, and agglutinogens 2 and 3 after infection with Bordetella pertussis and immunization with whole-cell pertussis vaccine. J Infect Dis 160, 838-845.

von König, C. H., Halperin, S., Riffelmann, M. \& Guiso, N. (2002). Pertussis of adults and infants. Lancet Infect Dis 2, 744-750.

Wilson, M. B. \& Nakane, P. K. (1978). Recent developments in the periodate method of conjugating hoseradish peroxidase (HRPO) to antibodies. In Immunofluorescence and Related Techniques, pp. 215-244. Edited by W. Knapp, K. Holubar \& G. Wick. Amsterdam: Elsevier.

Yih, W. K., Lett, S. M., des Vignes, F. N., Garrison, K. M., Sipe, P. L. \& Marchant, C. D. (2000). The increasing incidence of pertussis in Massachusetts adolescents and adults, 1989-1998. J Infect Dis 182, 1409-1416.

Zackrisson, G., Lagergård, T., Trollfors, B. \& Krantz, I. (1990). Immunoglobulin $\mathrm{A}$ antibodies to pertussis toxin and filamentous hemagglutinin in saliva from patients with pertussis. J Clin Microbiol 28, 1502-1505. 